\begin{tabular}{ccc}
\hline & International Journal of Engineering \& Technology, $7(4.1)(2018)$ 145-147 \\
SPC & International Journal of Engineering \& Technology \\
\hline
\end{tabular}

\title{
An Intelligent Control and Switching for the Optimization of Street Lighting
}

\author{
Jian-Ding Tan*, Sieh-Kiong Tiong, Siaw-Paw Koh, Kok Hen, Chong, Ying-Ying Koay \\ Institute of Sustainable Energy, Universiti Tenaga Nasional, 43000, Selangor, Malaysia \\ *Corresponding author E-mail: tjianding@uniten.edu.my
}

\begin{abstract}
The objective of this research is to propose an Artificial Intelligent method to optimize the performance of street lightings. The method proposed in this research is by using the Electromagnetism-Like Mechanism (EM) global optimization algorithm. The proposed EM is designed to minimize the power consumption and maximize the life span of the lamps by different switching configurations and by adjusting the intensities of the lights. Simulation results indicate that the proposed algorithm can significantly reduce the power consumption of the system and drastically increase the projected life span of the lamps used. The main power savings can be found in the early stages of the graph. This shows that the evening sun rays and twilight help illuminate the street, rendering full intensity of street lights a waste. This, in turn, significantly prolonged the lifespan of the lamps used in the street lightings. It can thus be concluded that the proposed algorithm gives significantly positive impact in optimizing the performance of a street lighting system. The search speed and accuracies of the EM can be further improved by modifying or incorporating other search mechanism into the EM in future extension of the research.
\end{abstract}

Keywords: Electromagnetism-Like mechanism algorithm; Optimization; Street lighting; Artificial intelligence.

\section{Introduction}

Street lighting is a crucial facility to ensure the safety on the road especially during night time or bad weather [1]. Studies show that well-lit city streets also helps reducing the criminal incidences [2]. However, the performance of a street light can be limited by several different reasons $[3,4]$. The conventional design of street lighting systems always pivot on two major issues, namely the energy consumption and the life span of the lamps. The maintenance of conventional street lightings alone can cost a huge bill to the township [3]. Smaller towns with lesser populations even opt out the installation of street lights due to the cost that comes along with it. Furthermore, the power demand from the street lightings proves to be a burden to utility companies, especially during high peak hours such as $7 \mathrm{pm}$ to $10 \mathrm{pm}$. It is reported that street light takes up to $3.19 \%$ of the worldwide electricity consumption [3].

A time-based, fixed on-off conventional street lighting facility operating at maximum intensity will only add on to the power supply issue at hand. Several approach has been proposed in the literature to refine and enhance the street lighting control systems, making it smarter and more dynamic. Kostic and Djokic conducted a study on the correlation between the rate of lighting and the energy saved [5]. Kotulski et al. proposed the optimization of street light energy efficiency via the photometric data obtained [6]. Gutierrez-Escolar et al. discussed some issues regarding the implementations of devices such as lamps, ballasts and street light globes based on the regulations on street lighting [7]. They then suggested several improvements and changes in the technology supply, lighting arrangements and the illumination levels from the street light.

Literature also shows that some studies aimed to improve on specific areas or issues instead of the overall integrated system. Most of them tend to improve and enhance the supply side of the system while neglecting the controller aspect of the lighting system. Several studies proved that the load power consumption shows significantly impact on the supply performance and energy consumption [8-10]. Thus, lighting switching and control that regulates the end load power consumption can have huge impact on the load demand and the overall performance of the street lighting system [11].

This paper proposed a new intelligent method to optimize the control and switching of street lighting systems. The contribution of this paper is two-fold and can be summarized along the lines as follows. Firstly, a global optimization algorithm known as the Electromagnetism-Like Mechanism (EM) algorithm is proposed to optimize the power consumption of street lightings by automatically switching and dimming the light arrays. Secondly, the proposed optimization algorithm also significantly prolonged the life span of the lamps used in the street lighting. The structure of the paper begins with the introduction and some research background in chapter one. Chapter two shows the details of the EM optimization algorithm proposed in this research. The setups of the experiments and the results obtained are discussed in chapter three. The final chapter offers some conclusions on the research findings.

\section{The Electromagnetism-Like Mechanism (EM) Algorithm}

The EM is a population based global optimization search mechanism first designed in [12]. The EM mimics the attraction-repulsion feature of electromagnetic charges in the theory of electromagnetism to reach a best optima point. The proposed algorithm considers all solutions as particles with different electromagnetic charges in the search space. The magnitude and polarity of the charges correlate with the value of the objective function of each. Particles that found relatively better solutions apply relatively attracting forces. Particles with relatively worse solutions, on the 
other hand, will push other particles away [13]. The magnitude of the forces varies with the difference of the objective values. The particles move at the end of each iteration based on superposition theorem. An example of the total force calculation is shown Figure 1. The total force on $\mathrm{Q}_{\mathrm{a}}$ (marked as $\mathrm{F}_{\mathrm{a}}$ ) is the combination of the pushing force from $\mathrm{Q}_{b}$ and pulling force from $\mathrm{Q}_{c}$. In this research, the EM is implemented to optimize the street lighting control by minimizing the power consumption and maximizing the life span of the lights, while keeping the illumination on the road to be above $8 \operatorname{lux}[14]$

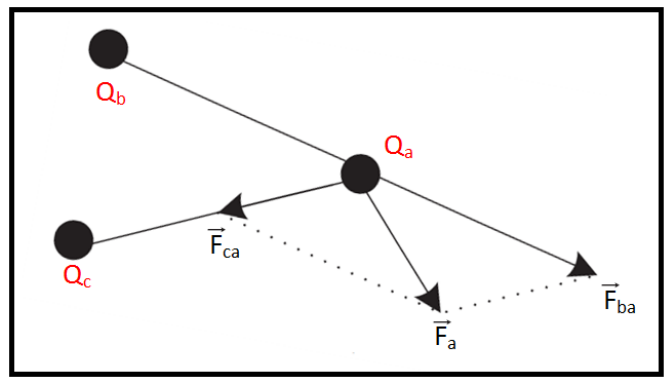

Fig. 1: $F_{a}$ generated from $F_{b a}$ and $F_{c a}$

A conventional EM is made of 5 main operations. The algorithm begins with the initialization, follows by the local search, the charge calculation, the force calculation, and finally the movement of al the particles except the best. Figure 2 shows the mechanism of the algorithm in each iteration.

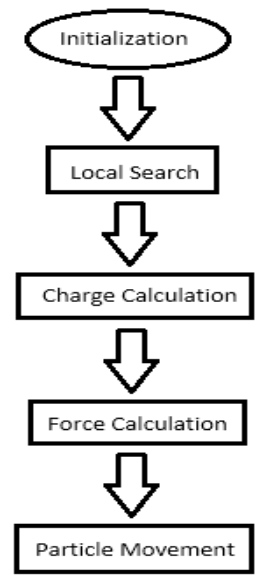

Fig. 2: EM mechanism in each iteration

The EM begins with the initialization stage, where random feasible solutions within the range of the tuning parameters are assigned to a pre-determined quantity of particles. Each of these particles now carries an $\mathrm{N}$ dimensional hyper-solid. In each of the dimension now lies uniformly distributed solution within the feasible upper and lower bound [15]. In this research, the optimization task required is to minimize the power consumption and maximize the life span of the lamps. For power consumption evaluation, the particle with the lowest function value is marked as the best particle. On the other hand, for lamp life evaluation, the best particle will be the particle with the highest function value.

In every global optimization algorithm, the local search is a crucial step to scrutinize the search in the local area for any possible solutions. The original local search procedure in a conventional EM employs a random line search within the feasible range of a solution. This simple line search involves a particle being tuned along its dimensions one by one, restricted by a step in random direction of the setting (brighter or dimmer as shown in Table 1). Each of the dim level will cause corresponding changes in other aspects, such as power consumption, lamp life, and illumination levels. Each iteration employs a new random size of step. The iteration loop ends immediately with any better objective value achieved.
Table 1: The settings of different lighting intensities and the corresponding parameters

\begin{tabular}{|c|c|c|c|c|}
\hline & $\begin{array}{c}\text { Lamp } \\
\text { Volt- } \\
\text { age(V) }\end{array}$ & $\begin{array}{c}\text { Lamp } \\
\text { Power(W) }\end{array}$ & $\begin{array}{c}\text { Illumina- } \\
\text { tions } \\
\text { (lm) }\end{array}$ & $\begin{array}{c}\text { Lamp } \\
\text { Life (H) }\end{array}$ \\
\hline Level 5 & 140 & 199 & 4774 & 9826500 \\
\hline Level 4 & 160 & 244 & 7498 & 1620000 \\
\hline Level 3 & 180 & 293 & 11165 & 330330 \\
\hline Level 2 & 200 & 345 & 15941 & 79657 \\
\hline Level 1 & 220 & 400 & 22000 & 22000 \\
\hline
\end{tabular}

The charge of each particle is calculated by comparing the objective value obtained by the particle to the best particle in the iteration. Each particle therefore effects all other particles based on the calculated objective value. By taking forces generated by all other particles into consideration, the total force vector exerted onto a particle can be determined using the Coulomb's Law. A force, be it attractive or repulsive, is determined by the calculated charge of a particle, $q^{i}$, in comparison to that of the others. The charge of a particle is determined based on equation (1)

$q^{i}=\exp \left(-n \frac{f\left(x^{i}\right)-f\left(x^{b e s t}\right)}{\sum_{k=1}^{m}\left(f\left(x^{k}\right)-f\left(x^{b e s t}\right)\right)}\right), \forall i$

where $n$ denotes the total dimension of the particle and $m$ refers to the population size. $f\left(x^{\text {best }}\right)$ is the objective value of the best particle. Upon completing the charge calculations, the total forces generated onto a particle can now be determined. Based on the electromagnetic theory, the force of one particle onto another is correlated to the distance between the two particles and the charge values [16]. Thus, the total force vector can be calculated by using equation (2), where $\mathrm{f}\left(\mathrm{x}_{\mathrm{j}}\right)<\mathrm{f}\left(\mathrm{x}_{\mathrm{i}}\right)$ refers to attraction force calculation and $\mathrm{f}\left(\mathrm{x}_{\mathrm{j}}\right) \geq$ $\mathrm{f}\left(\mathrm{x}_{\mathrm{i}}\right)$ denoted to repulsion force calculation.

$F^{i}=\sum_{j \neq i}^{m}\left\{\begin{array}{lll}\left(x^{j}-x^{i}\right) \frac{q^{i} q^{j}}{\left\|x^{j}-x^{i}\right\|^{2}} & \text { if } & f\left(x^{j}\right)<f\left(x^{i}\right) \\ \left(x^{i}-x^{j}\right) \frac{q^{i} q^{j}}{\left\|x^{j}-x^{i}\right\|^{2}} & \text { if } & f\left(x^{j}\right) \geq f\left(x^{i}\right)\end{array}\right\}, \forall i$

The search mechanism is then followed by the movement of particles to ensure a global search feature which grants the algorithm the ability to avoid local optima traps. In this stage, all the particles except the best are relocated to a new space to continue the search. This drastic relocation gives the algorithm a better exploration of more possible solutions with better settings. The movement of each particle is calculated based on equation (3), where $\lambda$ denotes the step of the particle movement. It is a step in random direction of light on-off setting, in which the combinations are shown in Table 2.

$x_{k}^{i} \leftarrow x_{k}^{i}+\lambda F_{k}^{i}\left(u_{k}-x_{k}^{i}\right) ; F_{k}^{i} \geq 0$

$x_{k}^{i} \leftarrow x_{k}^{i}+\lambda F_{k}^{i}\left(x_{k}^{i}-l_{k}\right) ; F_{k}^{i}<0$

Table 2: The setting of the on-off combinations

\begin{tabular}{|c|l|c|c|}
\hline & Setting A & Setting B & Setting C \\
\hline $\begin{array}{c}\text { Switching } \\
\text { Setting }\end{array}$ & All lights & $\begin{array}{c}\text { Every other } \\
\text { light ON }\end{array}$ & $\begin{array}{c}\text { One in three } \\
\text { lights ON }\end{array}$ \\
\hline
\end{tabular}

The best particle of the iteration does not move as it holds the absolute attraction force to all other particles [17]. After a pre-fixed number of iterations, the best optimized settings produced by the search algorithm is then fed into the actuator system set the lightings accordingly.

\section{Experimental Results}

The proposed algorithm was evaluated in a simulation for a group of 30 lights with of 400 watt each, luminous flux of $22000 \mathrm{~lm}$ each, and the life span of the lamps of 22000 hours each. The simulated streets are of fifteen meters width with 50 meters gap between poles Light detecting sensors placed in between all the lighting poles. Average values of a zone of three sensors will be calculated and taken into consideration. A constant value of 0.5 is set for light loss factor 
and utilization coefficient. The street lights are set to operate from $1800 \mathrm{H}$ to $0700 \mathrm{H}$ the next day. The simulated sunlight and ambient illuminations are as shown in Table 3. They are assumed to be uniformly distributed in the simulations. The EM was set to search for the best optimum values with 10 solutions particles. Simulations were carried out using an Asus X552L 64-bit laptop with Intel CORE i5 processor and $4 \mathrm{~Gb}$ RAM.

Table 3: Simulated ambient illumination from $1800 \mathrm{H}$ to $0700 \mathrm{H}$ the next day

\begin{tabular}{|c|c|}
\hline Time & Illumination (lux) \\
\hline $1800 \mathrm{H}$ & 20 \\
\hline $1830 \mathrm{H}$ & 15 \\
\hline $1900 \mathrm{H}$ & 10 \\
\hline $1930 \mathrm{H}$ & 5 \\
\hline $2000 \mathrm{H}$ & 2 \\
\hline $2030 \mathrm{H}-$ & 1 \\
$0600 \mathrm{H}$ & \\
\hline $0630 \mathrm{H}$ & 2 \\
\hline $0700 \mathrm{H}$ & 7 \\
\hline
\end{tabular}

Figure 3 shows the comparison of the power consumption before and after the implementation of the proposed optimization algorithm. It can be observed from the graph that the algorithm has significantly reduced the energy needed to light up the streets, especially from $1800 \mathrm{H}$ to $1930 \mathrm{H}$, when the ambient is still illuminated by the natural sun light during the twilight period. Even during the night, it is found that power saving is still possible by adjusting the switching and dimming levels of the street lights.

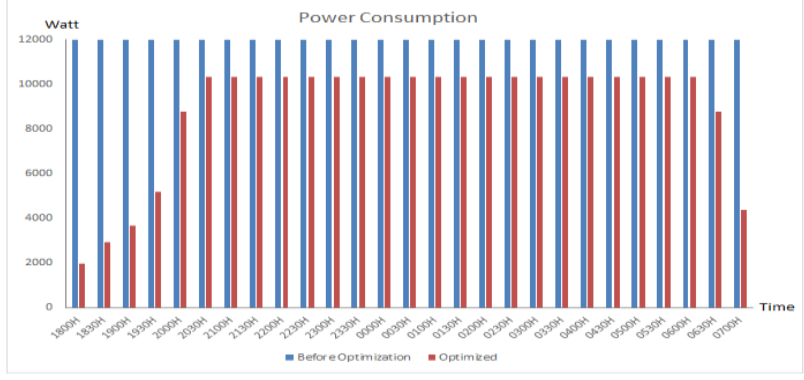

Fig. 3: Comparison on the power consumption before and after the implementation of the proposed optimization algorithm

Figure 4 shows the comparison of the projected lamp life before and after the implementation of the proposed EM. Note that the scale on the Y-axis is in logarithmic scale, which means that the optimization algorithm has significantly improved the life span of the street lights by dimming them of even switching them off when not needed. This, in turn, will significantly reduce the maintenance cost of the street light.

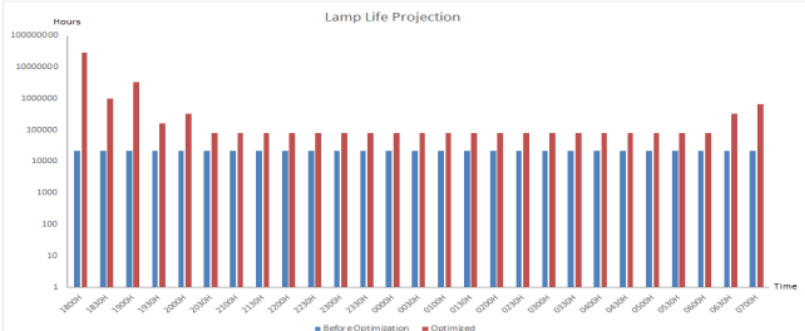

Fig. 4: Comparison on the projected lamp life before and after the implementation of the proposed optimization algorithm

\section{Conclusion}

In this research, an Electromagnetism-Like Mechanism algorithm $(\mathrm{EM})$ is proposed as an intelligent mean to optimize the efficiency of street lighting systems. The proposed EM was set to minimize the power consumption and maximize the life span of the lamps while meeting the criteria of street illuminations. Based on the readings from light intensity detecting sensors, the algorithm search for the best optimum settings by different switching configurations and different levels of dimming. Simulations results show that the algorithm significantly reduces the power consumption and drastically increase the life span of the lamps. We can thus conclude that the proposed algorithm performs well in optimizing the performance of street lighting arrays. Improvement on the local search mechanism of the algorithm and implementation in the actual system are considered for the extension of this research in time to come.

\section{Acknowledgement}

This research is supported by the Universiti Tenaga Nasional, Malaysia (UNITEN) under the 10289176/SMART/2018/09 SMART University grant.

\section{References}

[1] Liu C, Wang Q \& Zhang F, "Design and development of city streetlighting energy-saving system", 2010 Second Pacific-Asia Conf. Circuits, Commun. Syst, (2010), pp.0-4.

[2] Wu MS, Huang HH, Huang BJ, Tang CW \& Cheng CW, "Economic feasibility of solar-powered led roadway lighting", Renewable Energy, Vol.34, No.8, (2009), pp.1934-1938.

[3] Popa M \& Cepisca C, "Energy consumption saving solutions based on intelligent street lighting control system”, U.P.B. Sci. Bull. Ser. C, Vol.73, No.4, (2011), pp.297-308.

[4] Zhongshi L, Wei Z \& Hongxing H, "One novel optimum sizing method for solar lighting system by using genetic algorithm", 2009 Int. Conf. Energy Environ. Technol, (2009), pp.225-228.

[5] Kostic M \& Djokic L, "Recommendations for energy efficient and visually acceptable street lighting", Energy, Vol.34, Vol.10, (2009), pp.1565-1572.

[6] Kotulski L, De Landtsheer J, Penninck S, Sedziwy A \& Wojnicki I, "Supporting Energy Efficiency Optimization in Lighting Design Process" in Proceedings of 12th European Lighting Conference Lux Europa, (2013).

[7] Gutierrez-Escolar A, Castillo-Martinez A, Gomez-Pulido J, Gutierrez-Martinez J-M, Stapic Z \& Medina-Merodio J-A, “A study to improve the quality of street lighting in Spain", Energies, Vol.8, No.2, (2015), pp.976-994.

[8] Bilal BO, Sambou V, Ndiaye PA \& Kebe CMF, "Multi-objective Design of PV Wind-Batteries Hybrid Systems by Minimizing the Annualized Cost System and the Loss of Power Supply Probability ( LPSP )", 2013 IEEE International Conference on Industrial Technology (ICIT), (2013), pp.861-868.

[9] Bilal BO, Sambou V, Ndiaye PA, Kebe CMF \& Ndongo M, "Optimal design of a hybrid solarewind-battery system using the minimization of the annualized cost system and the minimization of the loss of power supply probability (LPSP)", Renew. Energy, Vol.35, No.10, (2010), pp.2388-2390

[10] Bilal BO, Sambou V, Ndiaye PA, Kebe CMF \& Ndongo M, "Study of the influence of load profile variation on the optimal sizing of a standalone hybrid PV/wind/battery/diesel system", Energy Procedia, Vol.36, (2013), pp.1265-1275.

[11] Suryoatmojo H, Artificial Intelligence Based Optimal Configuration of Hybrid Power Generation System, Thesis/Dissertation, (2010).

[12] Birbil SI \& Fang SC, "Electromagnetism-like mechanism for global optimization", Journal of Global Optimization, Vol.25, No.3, (2003) pp.263-282.

[13] Wu P, Hung YY \& Lin ZP, "Intelligent forecasting system based on integration of electromagnetism-like mechanism and fuzzy neural network", Expert Systems with Applications, Vol.41, No.6, (2014), pp.2660-2677.

[14] Marimuthu C \& Kirubakaran V, "Carbon and energy payback period for the solar street light using life cycle assessment", Int. J. Chem. Tech. Res, Vol.8, No.3, (2015), pp.1125-1130, 2015.

[15] Dutta R, Ganguli R \& Mani V, "Exploring isospectral cantilever beams using electromagnetism inspired optimization technique", Swarm and Evolutionary Computation, Vol.9, (2013), pp.37-46, 2013.

[16] Lee CH \& Lee YC, "Nonlinear systems design by a novel fuzzy neural system via hybridization of electromagnetism-like mechanism and particle swarm optimization algorithms", Information Sciences, Vol.186, No.1, (2012), pp. 59-72.

[17] Cuevas E, Oliva D \& Zaldivar D, "Pérez-Cisneros M, Sossa H., Circle detection using electro-magnetism optimization", Information Sciences, Vol.182, No.1, (2012), pp.40-55. 